\title{
El caso de las contrataciones de menos de 8 Unidades Impositivas Tributarias
}

Oscar Fernando Herrera Giurfa ${ }^{(t)}$

Abogado por la Pontificia Universidad Católica del Perú. Magíster en Derecho Administrativo Económico por el Instituto Ortega y Gasset. Magíster en Contrataciones Públicas por la Universidad Castilla de la Mancha.

Doctorando en Derecho en la Universidad San Ignacio de Loyola. Profesor de la Universidad de Lima, Universidad ESAN y Universidad San Ignacio de Loyola.

SUMARIO:

I. Introducción.

II. Los supuestos de inaplicación de la Ley de Contrataciones.

III. Las contrataciones hasta 8 Unidades Impositivas Tributarias.

IV. La base legal de las contrataciones hasta 8 Unidades Impositivas Tributarias.

V. Principales problemas encontrados en las contrataciones hasta 8 Unidades Impositivas Tributarias.

VI. Propuesta alternativa.

VII. Conclusiones. 


\title{
RESUMEN:
}

El mecanismo previsto en el ordenamiento jurídico peruano para las contrataciones de las entidades y empresas del Estado es a través de los procedimientos de selección según lo establece la Constitución de 1993, supuesto que se materializa mediante la Ley de Contrataciones del Estado. Sin embargo, esta norma contiene algunos supuestos que permiten su inaplicación. Dentro de estos supuestos de excepción, encontramos a las contrataciones de hasta 8 Unidades Impositivas Tributarias. En tal sentido, de la revisión efectuada a la Ley de Contrataciones, su Reglamento, los Decretos Supremos relacionados con las contrataciones públicas, las Directivas, las Opiniones de OSCE y nuestra experiencia de docente en Contrataciones Públicas, hemos podido advertir que el marco legal de las contrataciones de hasta 8 Unidades Impositivas Tributarias no se encuentra claramente establecido, salvo en los aspectos relacionados al registro de las mismas en el SEACE, tal como dispone el numeral 2 del artículo 5 de la Ley y el literal a) del artículo 11.2 de la Directiva Nº08-2017-0SCE/CD “Disposiciones aplicables al registro de información en el Sistema Electrónico de Contrataciones del Estado — SEACE". No obstante, y tal como desarrollamos en el presente artículo, subsiste la pregunta: ¿cuál es la normativa aplicable para las contrataciones hasta 8 UIT? En tal sentido y considerando que esta modalidad contractual es la más utilizada por las entidades públicas, considerando su cuantía, su celeridad, su flexibilidad, pretendemos abordar esta problemática e intentaremos proponer alternativas de solución a la misma.

Palabras clave: contrataciones de hasta 8 Unidades Impositivas Tributarias; procedimientos de selección; Ley de Contrataciones del Estado; Sistema Electrónico de Contrataciones del Estado — SEACE; normativa aplicable; entidades públicas.

\begin{abstract}
:
The mechanism laid out in the peruvian legal system for state entities and companies' procurement, is through selection procedures as established in the 1993 Constitution. This is materialized through the State Procurement Law. However, this law contains some cases that don't allow its application. Within these exceptional cases, we find contracts of up to 8 tax units — UIT-. In this sense, from the revision made to the Procurement Law, its Regulations, the Supreme Decrees related to public procurement, the Directives, the 0SCE opinions and our experience as a professor in Public Procurement, we have been able to realize that the legal framework for procurement up to 8 tax units is not clearly established, except in the aspects related to their registration in the SEACE, as provided in paragraph 2 of article 5 of the Law and subclause a) of article 11.2 of the Directive $N^{\circ}$ 008-2017-OSCE/CD "Provisions applicable to the registration of information in the Electronic System of State Procurement - SEACE". However, and as we develop in this article, the question remains: what is the applicable regulation for contracts up to 8 tax units? In this sense and considering that this contractual modality is the most used by public entities, considering its amount, its speed, its flexibility, we intend to address this problem and we will try to propose alternative solutions to it..

Keywords: public procurement up to 8 tax units; selection procedures; State Procurement Law; SEACE; applicable regulation; public entities.
\end{abstract}

\section{INTRODUCCIÓN}

El artículo 76 de la Constitución Política del Perú', establece:

"Las obras y la adquisición de suministros con utilización de fondos o recursos públicos se ejecutan obligatoriamente por contrata y licitación pública, así como también la adquisición o la enajenación de bienes. La contratación de servicios y proyectos, cuya importancia y monto señala la Ley de
Presupuesto se hace por concurso público. La ley establece el procedimiento, las excepciones y las respectivas responsabilidades."

Como se puede apreciar, el marco constitucional dispone que las entidades del sector público, con la finalidad de proveerse de los bienes, servicios u obras necesarias para el cumplimiento de sus funciones públicas y sus metas, se encuentran obligadas a desarrollar los procedimientos de selección descritos.

1. Constitución Política del Perú, promulgada el 29 de diciembre de 1993. 
En ese sentido, en el año 1997 se emitió la Ley $26850 .^{2}$ Fue el primer texto normativo que ordenó los sistemas de contrataciones públicas en nuestro país, ya que agrupó en un solo cuerpo legal los tres sistemas vigentes a la época, que diferenciaban los métodos de contratación de obras, bienes y servicios, y asesorías y consultorías: el Reglamento Único de Licitaciones y Contratos de Obras Públicas - RULCOP, el Reglamento Único de Adquisiciones para el Suministro de Bienes y la Prestación de Servicios No Personales - RUA y el Reglamento General de Asesorías y Consultorías - REGAC. La Ley 26850 incluyó los siguientes procedimientos de selección: Licitación Pública, Concurso Público, Adjudicación Directa y de Menor Cuantía.

Estos métodos de contratación permitían poder elegir la mejor alternativa dentro de las propuestas presentadas por los postores interesados, luego de lo cual se procedía a la suscripción del contrato correspondiente. Cabe señalar que la acotada norma no era de aplicación para las contrataciones cuyo monto era de hasta una Unidad Impositiva Tributaria —en adelante, "UIT"- . Este supuesto se aumentó a 3 UIT en la Ley de Contrataciones del Estado, aprobada mediante el Decreto Legislativo 1017. ${ }^{3}$ Sin embargo, este importe se aumentó a 8 UIT con la emisión de la Ley 30225, Ley de Contrataciones del Estado. ${ }^{4}$

El actual Texto Único Ordenado de la Ley de Contrataciones del Estado -en adelante, "TUO" y "Ley de Contrataciones del Estado" respectivamente-, aprobado mediante Decreto Supremo 082-2019-EF5, establece en su artículo 5 los supuestos excluidos del ámbito de aplica- ción de la ley, pero sujetos a supervisión del Organismo Supervisor de las Contrataciones del Estado - OSCE. Así, en el literal a) del numeral 5.1, señala que están sujetos a supervisión del OSCE, los siguientes supuestos excluidos de la aplicación de la ley: "Las contrataciones cuyos montos sean iguales o inferiores a ocho (8) Unidades Impositivas Tributarias, vigentes al momento de la transacción. Lo señalado en el presente literal no es aplicable a las contrataciones de bienes y servicios incluidos en el Catálogo Electrónico de Acuerdo Marco".

La tendencia es incrementar el importe de inaplicación de la normativa de contrataciones, supuesto que vemos confirmado en el proyecto de Ley de la Cadena de Abastecimiento ${ }^{6}$, que en literal j) de su artículo 64 establece: "Supuestos no sujetos a licitación o concurso ni a las reglas de ejecución contractual. Las contrataciones cuyos montos sean iguales o inferiores a 15 Unidades Impositivas Tributarias, vigentes al momento de la transacción".

Podemos apreciar que en los últimos 20 años, las entidades públicas han ganado terreno respecto a incrementar los montos de las contrataciones que se desarrollan sin utilizar la formalidad de la Ley de Contrataciones del Estado. Podemos entender que las entidades públicas requieran escenarios de acción con mayor flexibilidad para desarrollar contrataciones eficientes en costo y oportunidad; no obstante, lo que resulta muy preocupante es que no se haya desarrollado en todo este tiempo un mecanismo que sirva de base legal mínima para este tipo de contrataciones, que son, hoy en día, las más utilizadas por las entidades públicas.

2. Ley 26850, Ley de Contrataciones y Adquisiciones del Estado, publicada el 30 de julio de 1997.

3. Decreto Legislativo 1017, publicado el 4 de junio de 2008.

4. La Ley 30225 fue publicada en el diario oficial El Peruano el 11 de julio de 2014

5. Decreto Supremo N 082-2019-EF, publicado el 13 de marzo de 2019.

6. El 04 de octubre de 2020, el Ministerio de Economía y Finanzas, mediante Resolución Ministerial N²85-2020EF/54, prepublicó el Proyecto de Ley General de la Cadena de Abastecimiento Público. 


\section{LOS SUPUESTOS DE INAPLICACIÓN DE LA LEY DE CONTRATACIONES}

El artículo 3 de la Ley de Contrataciones del Estado dispone los supuestos de utilización de la misma por las entidades públicas, así como la relación de entidades y empresas públicas que deben utilizarla. De esta manera, encontramos que la totalidad de entidades, organismos públicos, organismos constitucionalmente autónomos, empresas públicas, gobiernos regionales, provinciales, locales y otros que utilicen fondos públicos, se encuentran obligados a utilizar la Ley de Contrataciones del Estado. No obstante, los artículos 4 y 5 de la acotada norma establecen aquellos supuestos excepcionales, que se encuentran excluidos del ámbito de aplicación de la misma, dividiendo dichos supuestos en dos grupos:

a) Aquellos en los que la exclusión se realiza sin supervisión del OSCE - previstos en el artículo 4-, como es el caso de los contratos bancarios y financieros, las contrataciones de notarios públicos, los servicios brindados por conciliadores, árbitros o miembros de la junta de resolución de disputas; $y$,

b) Aquellos supuestos sujetos a supervisión del OSCE — previstos en el artículo 5-, en los que encontramos por ejemplo a la contratación de servicios públicos, los convenios suscritos entre entidades, las contrataciones realizadas entre estados, y las contrataciones hasta 8 UIT.

En los casos antes descritos, las contrataciones que se enmarquen dentro de los supuestos excluidos del ámbito de aplicación de la normativa de contrataciones del Estado podrán realizarse sin observar las disposiciones - y las formalidades - de dicha normativa. No obstante, y tal como concluye la Opinión $N^{\circ}$ 200-2017DTN del OSCE:

"En una contratación cuyo monto sea igual o inferior a ocho (8) Unidades Impositivas Tributarias, vigentes al momento de la transacción, si bien no resultan aplicables las disposiciones de la normativa de contrataciones del Estado, la Entidad que requiera efectuarla debe observar los principios que rigen toda contratación pública así como garantizar la eficiencia y transparencia en el uso de los recursos públicos; lo cual la faculta a implementar mecanismos similares a los previstos en la normativa de contrataciones del Estado - como la aplicación de penalidades - a efectos de satisfacer su necesidad con dicha contratación."

Tal Opinión implica un marco mínimo indispensable que deben cumplir las entidades públicas al realizar contrataciones de hasta 8 UIT.

\section{LAS CONTRATACIONES HASTA 8 UIT}

Como hemos señalado, en la Ley 26850 se estableció que su aplicación era obligatoria para contrataciones que superaban 1 UIT. Luego, se debía utilizar un procedimiento de selección denominado Adjudicación de Menor Cuantía - AMC, el cual se utilizaba para contrataciones desde una UIT y hasta $S / 15,000.00$ en caso de servicios, hasta $S / 35,000.00$ para bienes, y hasta $S / 90,000.00$ para obras, como podemos apreciar en el caso de los servicios. Resulta anecdótico apreciar que el actual supuesto de inaplicación - previsto en el artículo 5 del TUO de la Ley de Contrataciones del Estado-incluiría todo el procedimiento de AMC.

En junio del 2008, mediante el Decreto Legislativo 1017, se aprobó una nueva Ley de Contrataciones del Estado, la cual en su artículo 3.3 estableció, en su literal h), que la norma no era de aplicación para las contrataciones cuyos montos sean iguales o inferiores a tres UIT vigentes al momento de la transacción. Es decir, se incrementó el supuesto de inaplicación de la norma anterior hasta las 3 UIT, lo que permitía una mayor flexibilidad a las contrataciones realizadas por el Estado hasta dicho monto. 
El 11 de julio de 2014 se publicó la Ley 30225, la cual en el literal a) del artículo 5.1 establece que la normativa de contrataciones del Estado no es aplicable para "las contrataciones cuyos montos sean iguales o inferiores a ocho (8) Unidades Impositivas Tributarias, vigentes al momento de la transacción". Precisando que, dichas contrataciones se encuentran sujetas a supervisión por parte del OSCE, supuesto que se materializa con la remisión mensual por parte de las entidades.

Como se puede apreciar, con el transcurrir de los años, la política respecto a las contrataciones realizadas por las entidades públicas exceptuándose de la aplicación de la normativa de contrataciones se ha incrementado, y de entrar en vigencia la Ley General de la Cadena de Abastecimiento Público — que ha vuelto a ser remitida por el Ministerio de Economía y Finanzas al Congreso para su aprobación-, este importe aumentará hasta 15 UIT, es decir S/ 66,000.00. Debemos advertir que esta suma contiene los topes máximos de los procedimientos de selección de consultores individuales - S/ 40,000.00 - y la comparación de precios - S/ 64,500.00—, los cuales serían considerados en el proyecto de Ley General de la Cadena de Abastecimiento Público.

Un elemento que resulta importante señalar es que si bien estamos ante un supuesto de inaplicación de la Ley de Contrataciones del Estado, según el artículo 5 del TUO de esta ley, este supuesto normativo contiene la obligación de las entidades de remitir al OSCE las contrataciones desarrolladas por montos de hasta 8 UIT en el transcurso del mes. En tal sentido, la Opinión $N^{\circ} 128-2017 / D T N$ del OSCE ${ }^{8}$ concluye que las entidades deben registrar y publicar en el Sistema Electrónico de Contrataciones del Estado - SEACE la información de estas contrataciones realizadas durante el mes, siendo el plazo máximo para ello el décimo día hábil del mes siguiente.

De este modo, el literal a) del artículo 11.2 de la Directiva N 008-2017-OSCE/CD - Disposiciones aplicables al registro de información en el SEACE—, regula específicamente el procedimiento de remisión de dichas contrataciones, no pudiendo utilizarse dicha como base legal para regular las contrataciones hasta 8 UIT.

\section{LA BASE LEGAL DE LAS CONTRATACIO- NES HASTA 8 UIT}

El artículo 5 de la Ley de Contrataciones del Estado, establece la inaplicación de la misma para las contrataciones de hasta 8 UIT. Asimismo, se establece que en los casos que la contratación supere 1 UIT, el contratista deberá contar con el Registro Nacional de Proveedor. También se establece la obligación de las entidades de remitir mensualmente al OSCE un reporte de las contrataciones realizadas hasta por dicho monto. Finalmente, el artículo 50 de la Ley de Contrataciones del Estado, que establece los supuestos sancionables a cargo del Tribunal de Contrataciones del Estado, incluye los casos de incumplimiento del contratista en las contrataciones de hasta 8 UIT. Más allá de estos aspectos, no hay mayor marco normativo para estas contrataciones que realizan las entidades públicas.

Considerando lo antes señalado, resulta sumamente relevante que la Opinión $\mathrm{N}^{\circ}$ 128-2017 concluya que las entidades que realicen contrataciones hasta 8 UIT deben efectuarlas de acuerdo a los lineamientos establecidos en sus normas de organización interna, en el marco de los principios que regulan la contratación pública, en razón de lo cual determinarán los mecanismos apropiados para garantizar la eficiencia y transparencia en el uso de los recursos públicos; de lo que se desprende que las entidades pueden implementar mecanismos similares a los establecidos en la normativa de contrataciones del estado para regular sus contrataciones de hasta 8 UIT.

Es en tal sentido que debemos entender la necesidad de que las entidades públicas emitan 
Directivas Internas que regulen las contrataciones de hasta 8 UIT que van a desarrollar. Lamentablemente, al revisar en internet, podemos advertir que son muy pocas las entidades que han publicado su Directiva Interna para realizar este tipo de contrataciones, lo que da como resultado que, en un universo de aproximadamente 2,300 entidades públicas, la gran mayoría de estas no cuentan con una base legal clara para desarrollar las contrataciones que utilizan más frecuentemente.

Para realizar el presente artículo, procedimos a revisar las directivas internas para contrataciones hasta 8 UIT de las principales entidades públicas de diversos sectores, como por ejemplo OSCE, Ministerio de Economía y Finanzas, EsSalud, Superintendencia Nacional de Aduanas y de Administración Tributaria - SUNAT, Defensoría del Pueblo, Presidencia del Consejo de Ministros, PROTRANSPORTE, Ministerio de Agricultura, Instituto Nacional de Salud del Niño, Organismo Supervisor de la Inversión en Infraestructura de Transporte de Uso Público OSITRAN, Gobierno Regional de Arequipa, entre otras, advirtiendo que las mismas incluyen como base legal las siguientes normas: Ley de Presupuesto, TUO de la Ley de Contrataciones del Estado, el Reglamento de Organización y Funciones de cada entidad y el Código Civil. No terminamos de entender por qué algunas entidades han incluido dentro de su base legal al Código Civil, que es una norma diseñada para la contratación entre particulares y no es la herramienta adecuada para las contrataciones realizadas por la administración pública. Sobre el particular, García de Enterría y Fernández ${ }^{9}$ sostienen:

"Por lo pronto, hay que decir que el Derecho Administrativo es un Derecho Público, del que constituye una de sus ramas más importantes. Siendo la Administración Pública la única personificación interna del Estado, cuyos fines asume, y siendo también dicha persona el instrumento de relación permanente y general con los ciudadanos (en tanto que las funciones no administrativas del Estado son de actuación intermitente y, o bien no se expresan en un sistema de relaciones jurídicas con los ciudadanos, o cuando esto ocurre, tales relaciones afectan sólo a contados y excepcionales sujetos), es lícito decir que el Derecho Administrativo es el Derecho Público del Estado por excelencia".

Un aspecto relevante que se debe tener en cuenta al considerar la base legal de estas directivas a la Ley del Procedimiento Administrativo General, es lo señalado por Manuel María Diez ${ }^{10}$ cuando precisa que la ley administrativa puede ser de relación o de organización y acción administrativa:

"Las leyes administrativas se clasifican teniendo en cuenta su contenido. Hay normas de relación y normas de organización y acción administrativa. Las normas de relación son aquellas que se dictan para delimitar las esferas jurídicas subjetivas de la administración y de los particulares. Son leyes que atribuyen a veces poderes jurídicos y facultades a la administración pública, pero también son las que vienen a proteger directamente las situaciones jurídicas de los particulares, convirtiéndolas en derechos subjetivos oponibles frente al Estado. En lo que se refiere a las normas de organización y acción administrativa, son aquellas que determinan, por una parte, la estructura orgánica de la administración pública, y por otra, los fines propios que la administración ha de perseguir con su actuación y el modo y forma como esto debe realizarse. Estas normas no se dictan para garantía de los derechos subjetivos de los particulares, sino para la tutela del interés público".

9. García de Enterría, García de Enterría y Ramón Fernandez. Curso de Derecho Administrativo I (Madrid: Editorial Civitas S.A., 1977), 38 - 39.

10. María Diez, Manuel. Manual de Derecho Administrativo (Madrid: Plus Ultra, 1985), 317 - 318 
Por lo expuesto, entendemos que no resulta eficiente incluir al Código Civil o la Ley del Procedimiento Administrativo General dentro de la base legal para las contrataciones públicas de hasta 8 UIT; pero sí resulta necesario implementar una directiva modelo que puedan utilizar las entidades para regular dichas contrataciones.

\section{PRINCIPALES PROBLEMAS ENCONTRA- DOS EN LAS CONTRATACIONES HASTA 8 UIT}

El primer problema que hemos advertido respecto a estas contrataciones es el de su denominación. En tal sentido, podemos decir que es muy frecuente denominar a estas contrataciones como "Contrataciones Directas". Sobre el particular debemos señalar que el artículo 27 del TUO de la Ley 30225 establece cada uno de los supuestos en los cuales, excepcionalmente, las entidades pueden contratar directamente con un determinado proveedor sin necesidad de realizar un procedimiento de selección. Como podemos advertir, dicho supuesto es distinto a la inaplicación de la Ley de Contrataciones del Estado. En ese sentido, de manera específica el artículo 102 del Reglamento de la Ley de Contrataciones del Estado establece que: "Las actuaciones preparatorias y contratos que se celebren como consecuencia de las contrataciones directas cumplen con los requisitos, condiciones, formalidades, exigencias y garantías establecidos en la Ley y el Reglamento(...)". Como podemos apreciar, en las "Contrataciones Directas" sí se aplica la Ley de Contrataciones del Estado, mientras que en las contrataciones de hasta 8 UIT no se aplica. Por ende, resulta un error denominarlas de igual forma, pues son supuestos distintos.

Un segundo problema que advertimos es respecto a la utilización de esta modalidad de contratación para incurrir en supuestos que la norma considera como fraccionamiento. El artículo 20 del TUO de la Ley 30255 establece:

"Se encuentra prohibido fraccionar la contratación de bienes, servicios u obras con la finalidad de evitar el tipo de procedimiento de selección que corresponda según la necesidad anual, de dividir la contratación a través de la realización de dos o más procedimientos de selección, de evadir la aplicación de la presente norma y su reglamento para dar lugar a contrataciones iguales o inferiores a ocho (8) UITy/o evadir el cumplimiento de los tratados o compromisos internacionales que incluyan disposiciones sobre contratación pública" - el subrayado es nuestro-.

Como podemos advertir, el fraccionamiento consiste en dividir una contratación de un monto mayor en contrataciones de importes menores. Es decir, en lugar de desarrollar un procedimiento de Adjudicación Simplificada por la suma de S/ 50,000.00 para la contratación del servicio de mensajería, contrato dicho servicio mediante dos contrataciones de S/ 25,000.00, las cuales desarrollaré sin utilizar la Ley de Contrataciones del Estado. Este supuesto es muy utilizado para realizar contrataciones más rápidas y que podrían considerarse eficientes; no obstante, en muchos casos se utiliza esta modalidad para contratar solamente a un grupo determinado de proveedores los cuales gozan de la simpatía del órgano de contrataciones de la entidad, lo que lamentablemente, no solo implica quebrantar los principios de Libertad de Concurrencia o de Igualdad de Trato, entre otros, sino que en muchos casos implica actos de contubernio entre las partes o incurrir en delitos de corrupción de funcionarios, como colusión o cohecho.

Un tercer problema que advertimos de las contrataciones de hasta 8 UIT es que ninguna de las partes tiene claro qué puede hacer en caso una de ellas incumpla con sus prestaciones. En este supuesto, la entidad sí tiene una ventaja respecto al contratista, considerando que el artículo 50 de la Ley de Contrataciones del Estado establece como supuesto de sanción por el Tribunal de Contrataciones del Estado el negarse injustificadamente a cumplir las obligaciones derivadas del contrato que deben ejecutarse con posterioridad al pago, incluso si dicha contratación es menor a 8 UIT. En tal sentido, el contratista que incumple injustificadamente su obligación contractual con la entidad, podrá

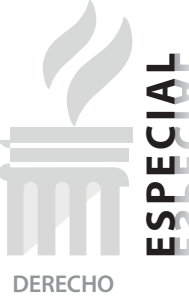


ser sancionado por el Tribunal de Contrataciones del Estado, incluso si dicha contratación es inferior a los $S / 35,200.00$. No obstante, no hay ninguna norma que establezca cuales son las alternativas que tiene el contratista en caso la entidad no cumpla con su obligación de pago en un contrato menor a 8 UIT. Y lo que es peor, no se ha establecido mecanismo alguno de solución de controversias respecto a estas contrataciones, lo que limita al contratista, en caso de incumplimiento de la entidad, a tener que acudir al Poder Judicial para entablar un proceso civil y obtener el pago de la suma de S/ $35,200.00$ o menos, mientras que un contratista que suscribió un contrato dentro de los alcances de la Ley de Contrataciones del Estado tiene la posibilidad de resolver su controversia contractual mediante conciliación y/o arbitraje, ambos mecanismos mucho más céleres que el Poder Judicial.

Somos conscientes de que, el lector que ha tenido una relación contractual con el Estado por montos inferiores a las 8 UIT, puede advertir la existencia de otros problemas; sin embargo, en el presente artículo hemos creído conveniente enfocarnos solo en los más importantes.

\section{PROPUESTA ALTERNATIVA}

Si bien la Opinión № 128-2017, en su segunda conclusión, establece que las entidades que realicen contrataciones por hasta 8 UIT deben efectuarlas de acuerdo a los lineamientos establecidos en sus normas de organización interna, lo que implica la posibilidad de que cada entidad desarrolle su propia Directiva. Lamentablemente, son muy pocas las entidades que han logrado elaborar esta herramienta legal.

En tal sentido, y tomando como base lo señalado en la opinión acotada y lo previsto en la Directiva para contrataciones cuyos montos sean iguales o inferiores a 8 UIT en el OSCE ${ }^{11}$, proponemos como una alternativa de solución a los problemas planteados que el OSCE, dentro de las atri- buciones que le confiere el artículo 52 de la Ley de Contrataciones del Estado - como son: velar y promover que las Entidades realicen contrataciones eficientes bajo los parámetros de la ley y la gestión por resultados, así como la facultad de emitir directivas, en materia de su competencia- emita una Directiva que regule las contrataciones hasta 8 UIT. Esta directiva debe incluir:

a) Finalidad: regular la contratación de bienes, servicios y consultorías por montos iguales o inferiores a 8 UIT.

b) Alcances: las disposiciones contenidas en la presente Directiva son de aplicación y cumplimiento obligatorio para todas las entidades y empresas públicas señaladas en el artículo 3 de la Ley de Contrataciones del Estado que no cuenten con normativa interna que regule las contrataciones hasta 8 UIT.

c) Base Legal: Ley General del Sistema Nacional de Presupuesto, Texto Único Ordenado de la Ley de Contrataciones del Estado, Reglamento de la Ley de Contrataciones del Estado, Decreto Supremo que aprueba los lineamientos de Organización del Estado.

d) Definiciones: las definiciones elementales de los principales agentes intervinientes en la contratación.

e) Responsabilidad: la responsabilidad específica de cada uno de los agentes que intervienen en la contratación.

f) Disposiciones generales y específicas: aquí se incluirán los aspectos comunes y específicos de las contrataciones de hasta 8 UIT desde su convocatoria a través de la página web de la entidad.

g) Mecanismos de solución de controversias: para los contratos hasta 8 UIT, materializados a través de órdenes de compra y de órdenes de servicio, proponiendo para tal fin

11. Directiva aprobada mediante Resolución de Presidencia de Consejo Directivo Nº001-2019-OSCE/SGE. 
un arbitraje especial a cargo del Sistema Nacional de Arbitraje OSCE, con un honorario fijo mínimo por todo concepto, y con una duración máxima de 30 días incluida la audiencia única y emisión de laudo.

Considerando que la emisión de las directivas es una facultad que la Ley de Contrataciones del Estado le atribuye al OSCE, no es necesario mayor cambio normativo, que la emisión de una Resolución de Presidencia de OSCE.

\section{CONCLUSIONES}

Si bien la Ley de Contrataciones del Estado debe ser utilizada por todas las entidades y empresas del Estado, la misma contempla supuestos excluidos de su aplicación, como es el caso de las contrataciones de hasta 8 UIT.

Son muy pocas las entidades que han regulado las contrataciones hasta 8 UIT mediante directivas internas, lamentablemente, en la gran mayoría de entidades no se ha regulado esta contratación.
La falta de una normativa adecuada respecto a las contrataciones de hasta 8 UIT genera que muchas entidades de manera errónea utilicen el Código Civil para regular contrataciones que incluyen interés público.

Otro aspecto preocupante, es que la falta de ADMINISTRATIVO regulación adecuada ocasiona supuestos de fraccionamiento y/o direccionamiento en las contrataciones de hasta 8 UIT al no existir un marco legal claro que regule el procedimiento para la contratación, más allá de la Directiva que regula la remisión de la información al OSCE.

Teniendo en cuenta que las contrataciones hasta 8 UIT también incluyen el interés público y se pagan con fondos públicos, los cuales deben ser utilizados eficientemente, es necesario que el OSCE elabore una Directiva que sirva de base legal para las contrataciones hasta 8 UIT, la cual debe incluir por lo menos los procedimientos de dicha contratación, los mecanismos de convocatoria, así como los medios de solución de controversias de la misma. 